\title{
Prompt initiation of maintenance treatment following a COPD exacerbation: outcomes in a large insured population
}

This article was published in the following Dove Press journal:

International Journal of COPD

8 June 2016

Number of times this article has been viewed

\author{
Anna D Coutinho' \\ Tasneem Lokhandwala' \\ Robert L Boggs ${ }^{2}$ \\ Anand A Dalal ${ }^{2}$ \\ Pamela B Landsman- \\ Blumberg' \\ Julie Priest ${ }^{2}$ \\ David A Stempel ${ }^{3}$
}

'Real World Evidence, Xcenda LLC, Palm Harbor, FL, ${ }^{2}$ US Health

Outcomes, GlaxoSmithKline, Research Triangle Park, NC, ${ }^{3}$ US Medical Affairs, GlaxoSmithKline, Research Triangle Park, NC, USA
Correspondence: Anna D Coutinho Xcenda LLC, 4 II 4 Woodlands Parkway, Suite 500, Palm Harbor, FL 34685, USA

Tel + I $5 \mid 3474$ I528

Fax +l 727 77| 4145

Email anna.coutinho@xcenda.com
Background: The aim of this study was to extend previous findings and determine the value of prompt initiation of maintenance treatment (MT) following COPD exacerbations requiring hospitalization or an emergency department (ED) visit.

Patients and methods: Administrative claims data (collected between January 1, 2009 and June 30, 2012) from an employer-sponsored commercially insured population were retrospectively used to identify patients with a COPD exacerbation resulting in hospitalization or an ED visit. Patients initiating approved MT for COPD within 30 days of discharge/diagnosis (prompt) were compared with those initiating MT within 31-180 days (delayed). COPD-related total, medical, and prescription drug costs during a 1-year follow-up period were evaluated using semilog ordinary least square regressions, controlling for baseline characteristics plus COPDrelated costs from the previous year. The odds and number of subsequent COPD-related exacerbations during the follow-up were compared between the prompt and delayed cohorts using logistic regression and zero-inflated negative binomial models, respectively.

Results: A total of 6,521 patients with a COPD-related hospitalization or an ED visit were included, of whom 4,555 received prompt MT and 1,966 received delayed MT. Adjusted COPD-related total and medical costs were significantly lower for the prompt MT than the delayed MT cohorts (US\$3,931 vs US $\$ 4,857$ and US\$2,327 vs US\$3,087, respectively; both $P<0.010$ ), as were COPD-related prescription costs (US $\$ 1,526$ vs US $\$ 1,683, P<0.010$ ) during the 1-year follow-up period. Patients receiving delayed MT were $68 \%$ more likely to have a subsequent exacerbation requiring hospitalization and $80 \%$ more likely to have an exacerbation requiring an ED visit.

Conclusion: Prompt initiation of MT following a COPD-related hospitalization or an ED visit was associated with a significant reduction in COPD-related costs and odds of exacerbation in the following year compared with delayed initiation.

Keywords: COPD, maintenance treatment, costs, exacerbations

\section{Introduction}

COPD is characterized by persistent airflow obstruction and is a major cause of ill health worldwide. ${ }^{1}$ Within USA, COPD has been estimated to have annual costs of US\$75 billion for a nationally representative population (4.6 million individuals $)^{2}$ and US $\$ 15.7$ billion for commercially insured patients (2.9 million individuals). ${ }^{3}$ Direct health care costs account for 39\%-73\% of these total costs, ${ }^{4}$ and the major component of these direct costs is hospitalization. ${ }^{2,3}$ Exacerbations are also a significant contributor to COPD-related costs, as patients with COPD exacerbations have ten times the annual health care costs of patients without exacerbations. ${ }^{5}$ However, economic costs are 
not the only developmental driver of more effective COPD treatments, as understanding and improving the quality of COPD care are the priorities within the US health care organizations..$^{6,7}$

A study has shown that the quality of care of patients with COPD in a commercially insured population is suboptimal, with a substantial proportion of patients being $<80 \%$ compliant with their prescribed medication. ${ }^{8}$ Improvement in the quality of care can be aided by the development of performance measures, which ultimately help patients achieve the best possible outcomes. ${ }^{7,8}$ The Centers for Medicare and Medicaid Services implemented a National Quality Foundation endorsed performance measure in $2015 .^{9}$ This involves strictly monitoring COPD-related hospital readmissions within 30 days of the first exacerbation. ${ }^{9,10}$ Such strategies are aimed at improving the quality of care and could potentially reduce the economic costs of COPD. ${ }^{8}$

Therapies such as long-acting $\beta_{2}$-agonists (LABAs), long-acting muscarinic antagonists (LAMAs), and inhaled corticosteroids (ICS) are central to the pharmacological management of patients with moderate-to-severe COPD, according to the Global initiative for chronic Obstructive Lung Disease (GOLD) guidelines. ${ }^{1}$ Initiation of maintenance treatment (MT) with these agents has been shown to benefit patients through a reduction in exacerbations and hospitalizations. ${ }^{1,11,12}$ However, only one empirical study to date has shown the importance of the timing of MT initiation. ${ }^{13,14}$ At the time of that empirical study, fewer MT options were available, and therefore it included ICS and ipratropium as MTs. ${ }^{14}$ However, ICS and ipratropium were not recommended as MTs for patients with COPD according to the GOLD 2014 guidelines, ${ }^{15}$ and hence not included in this study. With these changes to the 2014 guidelines, it was imperative that the timing of MT initiation was analyzed using up-to-date treatments. This study aimed to confirm and extend the previous findings by including the different range of MTs that are currently recommended for patients with COPD.

The primary objective of this study was to compare the impact of prompt ( $\leq 30$ days) vs delayed (31-180 days) MT initiation following a COPD exacerbation requiring hospitalization or an emergency department (ED) visit on COPD-related costs. The odds and number of subsequent COPD-related exacerbations were also assessed.

\section{Patients and methods}

\section{Study design and population}

This is an observational cohort study using the data obtained from a retrospective database of paid health care claims with dates of service between January 1, 2008, and June 30, 2013. The target population consisted of patients with a COPD exacerbation, which was defined as a hospitalization with a discharge diagnosis of COPD (International Classification of Diseases-9 codes: 491.xx, 492.xx, 496.xx ${ }^{16}$ ) or an outpatient ED visit (with a primary diagnosis of COPD) in the enrollment period (January 1, 2009 to June 30, 2012; Figure 1).

The index date was defined as the date of the first hospital discharge or ED visit for COPD exacerbation. A 1-year pre-index period (prior to the admission date of the index hospitalization or the date of the index ED visit) was used for the baseline assessment, and a 1-year follow-up period starting on the index date was used to evaluate the study outcomes. Patients receiving MT (which included all treatments approved for COPD: LABAs, LAMAs, methylxanthines, and combinations of LABA/LAMA/ICS and excluded ICS monotherapy and any unapproved [off-label] COPD treatments) 180 days post-index were stratified into two study cohorts. The prompt MT cohort consisted of patients with

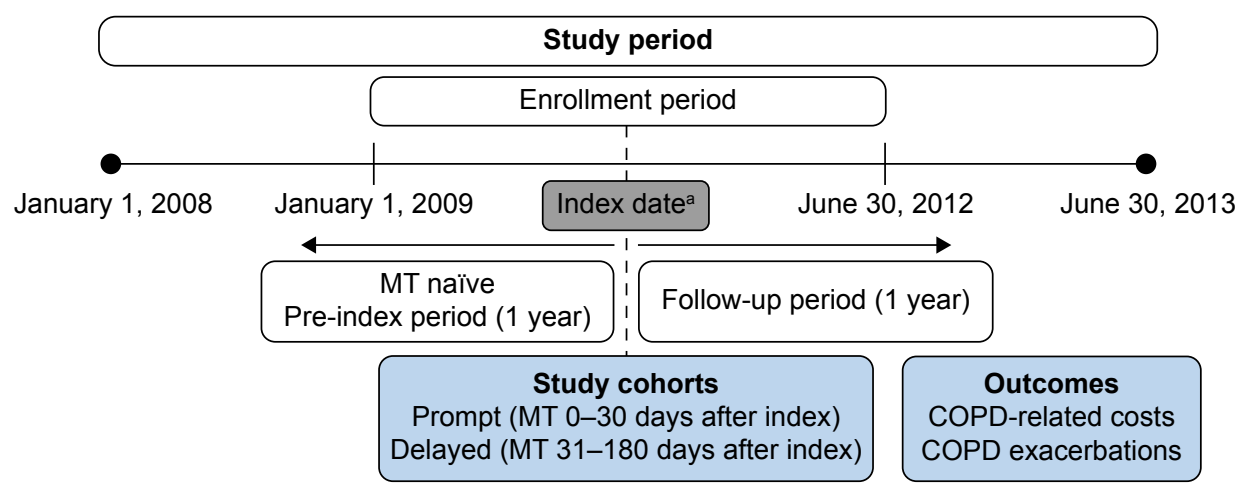

Figure I Study design.

Notes: ${ }^{\text {DD }}$ ischarge date after the first chronologically occurring COPD exacerbation resulting in hospitalization or an ED visit. Abbreviations: ED, emergency department; MT, maintenance treatment. 
a prescription fill for MT within 30 days of their index exacerbation. The delayed MT cohort comprised patients with a prescription fill for MT between 31 days and 180 days post-index. Patients were also required to be $\geq 40$ years of age and continuously enrolled in a health plan during the preindex and follow-up periods for inclusion in the study.

Exclusion criteria included the use of MT prior to the index event, diagnosis of other lung diseases, and the presence of at least one claim paid under capitated cost.

Permitted non-maintenance COPD medications available by prescription were short-acting $\beta_{2}$ agonists, short-acting muscarinic antagonists, oral corticosteroids (OCSs), and antibiotics.

Institutional Review Board (IRB) approval and patient consent to conduct this study was not sought because the MarketScan Research Databases fall under the 45 CFR 46.101(b)(4) exemption from IRB review in US Department of Health and Human Services (HHS) regulations (Title 45 of the Code of Federal Regulations, Part 46).

\section{Data source}

Data were obtained from the Truven Health MarketScan ${ }^{\mathrm{TM}}$ Commercial Claims and Encounters Database (Commercial) and Medicare Supplemental and Coordination of Benefits Database (Medicare Supplemental). The Commercial database consists of medical and drug claims data from employers and health insurance plans for more than 40 million enrollees per year. Enrollees are employees, their spouses, and dependents covered by employer-sponsored private health insurance. The Medicare Supplemental database consists of inpatient and outpatient medical and prescription claims for more than three million enrollees per year. Enrollees are retirees and their dependents with supplemental insurance plans offered by their former employers. Unique patient identifiers allowed patients to be followed longitudinally as they moved from the Commercial to the Medicare Supplemental database when claims for both were available. Patient data from both databases were pooled for these analyses.

\section{Study outcomes}

All outcomes were assessed during a 1-year follow-up period from the index date. The primary end point was COPDrelated costs, which were defined as the total amount paid to all providers, insurers, and patients, for medical claims with a primary diagnosis of COPD and prescription claims for COPD-related MT and non-maintenance medication, standardized to 2013 USD using the medical component of the Consumer Price Index. ${ }^{17}$
The secondary end points were COPD-related exacerbations and the components of COPD-related medical costs. COPD-related exacerbations were defined as an event resulting in 1) hospitalization with a discharge diagnosis of COPD , 2) an ED visit with a primary diagnosis of COPD, or 3) a physician visit with a primary diagnosis of COPD and prescription fill for an OCS or antibiotic within 5 days. Multiple exacerbations occurring within a single 14-day period were counted as one event. ${ }^{18}$ When multiple exacerbations occurred, a hierarchy was used to assign the encounter type as follows: hospitalization, ED visit, and physician visit + prescription. Components of COPD-related medical costs included hospitalizations, ED visits, physician visits, laboratory, radiology, and other outpatient services. Other services included, but were not limited to, anesthesia, miscellaneous surgical procedures, lesion removal, ambulance services, parenteral nutrition, and use of catheters.

\section{Statistical analyses}

Inferential statistics were used to compare patient characteristics between the study cohorts at baseline, including Student's $t$-tests for continuous variables and chi-square tests for categorical variables.

Post-index COPD-related costs were analyzed using multivariable semilog ordinary least squares (OLS) models based on data distribution diagnostics, ${ }^{19}$ with a smearing factor adjustment. ${ }^{20}$ For the total and prescription costs, a one-part semilog OLS analysis was used. For the medical costs, a two-part model was used, comprising a logistic regression model to obtain the probability of incurring nonzero costs, followed by a semilog OLS model for all patients with nonzero costs. Individual components of the overall medical costs were analyzed using a similar two-part generalized linear model.

Bootstrap methods were used to obtain $95 \%$ confidence intervals (CIs) for the estimates of the differences in mean adjusted costs for both primary and secondary end points. Bootstrap samples (1,000 iterations) of the same size as the analytic dataset were created and the models run (reestimating the coefficients for all independent variables at each iteration). The percentile method was used to compute the 95\% CIs, and if the estimated 95\% CI for the difference in costs did not contain 0 the difference was deemed significant at $P<0.050$. In addition, differences in primary cost end points (COPD-related total, medical, and pharmacy costs) were assessed at $P<0.010$ using $99 \%$ CIs.

The relative odds ratio for the prompt vs delayed MT cohorts for the odds of having a subsequent COPD exacerbation 
was obtained using a multivariable logistic regression model. Incidence rate ratios for the relative difference in the number of COPD exacerbations between the cohorts were obtained using a zero-inflated negative binomial model.

All multivariable models controlled for index exacerbation type and baseline measures of age, sex, region, overall comorbidity, and COPD severity in the pre-index period. Pre-index COPD-related costs were included as a covariate in the cost models. Patient's overall comorbidity burden was assessed using four measures: the Dartmouth-Manitoba adaptation $^{21}$ of the Charlson Comorbidity Index (CCI), ${ }^{22}$ the number of unique prescription classes and diagnoses, and the presence of specific non-CCI comorbidities in the pre-index period. COPD disease severity was estimated using several proxies: the use of inhaled short-acting muscarinic antagonists, the number of short-acting $\beta_{2}$ agonist canisters, OCS use, antibiotic use, home oxygen therapy use, mechanical ventilation/intubation during hospitalization or ED visit in the pre-index period, the presence of COPD-related exacerbations in the pre-index period, and COPD-related total costs in the pre-index period.

\section{Results}

During the enrollment period, there were 64,838 patients with a COPD exacerbation, who received MT within 180 days of that exacerbation. Of those, 6,521 patients met all the study inclusion criteria. The main reasons for the study exclusion were the lack of continuous eligibility during the 1-year pre-index through 1-year post-index period and the receipt of MT in the pre-index period. The final study population consisted of 4,555 (69.9\%) patients who received prompt MT and 1,966 (30.1\%) who received delayed MT.

More than half of the patients in the final population were female $(55.1 \%)$ and $53.5 \%$ were 65 years of age or older. The CCI was similar between the cohorts, but there were significant differences in the proportions of patients with specific diseases (eg, asthma was significantly higher in the delayed [17.0\%] vs the prompt [12.3\%] cohorts, $P<0.001$; Table 1). Most of the proxies for COPD severity were greater in the delayed cohort compared with the prompt cohort (Table 1).

After adjusting for baseline covariates, post-index COPDrelated costs were significantly lower for the prompt MT cohort (US\$3,931, 95\% CI: US\$1,438-US\$11,519) vs the delayed MT cohort (US\$4,857, 95\% CI: US\$1,900-US\$13,310; $P<0.010)$. This was mainly due to the difference in mean baseline-adjusted medical costs, which were US\$760 lower in the prompt MT cohort than the delayed MT cohort (US\$2,327 vs US\$3,087; $P<0.010$ ). The mean annual adjusted COPD-related prescription costs were also significantly lower for the prompt (US\$1,526, 95\% CI: US\$595US\$4,128) compared with the delayed (US\$1,683, 95\% CI: US\$511-US\$4,271; $P<0.010$ ) MT cohort (Figure 2).

Overall, $31.8 \%$ of the study sample had at least one subsequent exacerbation in the 1-year follow-up period. When the timing of MT initiation was compared, the delayed MT cohort had a $68 \%$ higher odds of a COPD exacerbation $(P<0.001)$, which was driven mainly by an $80 \%$ higher odds of exacerbations requiring an ED visit compared with the prompt MT cohort (Figure 3A). The delayed MT cohort also had a 29\% higher incidence of any COPD exacerbation type $(P=0.001)$, which was again driven mainly by a $45 \%$ higher incidence of exacerbations requiring an ED visit, compared with the prompt MT cohort (Figure 3B).

Post-index costs relating to hospitalization were the largest contributor of medical costs, accounting for US\$1,280 (95\% CI: US\$11-US\$29,014) within the prompt MT cohort and US\$1,564 (95\% CI: US\$21-US\$27,847; $P \geq 0.05)$ of costs for the delayed MT cohort (Figure 4). The prompt MT cohort had significantly lower costs relating to ED visits (36.7\% lower), physician visits (12.1\% lower), and other outpatient services (39.0\% lower) compared with the delayed MT cohort (all $P<0.050$; Figure 4).

A sensitivity analysis was conducted to determine the robustness of the cohort definitions, where the prompt cohort was defined as the initiation of MT within 15 days of the index exacerbation and the delayed cohort between 16 days and 180 days. The results of this sensitivity analysis were generally consistent with the main analyses, in both direction and magnitude.

\section{Discussion}

The initiation of MT within 30 days of a COPD-related exacerbation was associated with a significant reduction in total direct COPD-related costs compared with the delayed MT initiation during the 1-year follow-up period. Significant reductions in both the medical and prescription costs were observed in the prompt vs delayed MT cohorts. Patients in the prompt MT cohort were also less likely to suffer a subsequent exacerbation resulting in hospitalization, an ED visit, or a physician visit plus a prescription within 5 days. This decreased likelihood was mainly driven by the lower odds of an exacerbation resulting in an ED visit.

This study confirms the previous findings by Dalal et al, ${ }^{14}$ demonstrating similar trends in total and medical costs, but the numerical differences between the prompt and delayed MT cohorts were much larger in the prior study (differences in both were over US\$1,000 ${ }^{14}$ vs under US\$1,000 here). 
Table I Baseline demographics and characteristics

\begin{tabular}{|c|c|c|c|c|}
\hline Demographic characteristics & $\begin{array}{l}\text { Total } \\
(\mathrm{N}=6,521)\end{array}$ & $\begin{array}{l}\text { Prompt MT } \\
(n=4,555)\end{array}$ & $\begin{array}{l}\text { Delayed MT } \\
(n=I, 966)\end{array}$ & $P$-value ${ }^{a}$ \\
\hline Age, mean (SD) years & $67.4(12.0)$ & $66.9(11.8)$ & $68.4(12.2)$ & $<0.001$ \\
\hline \multicolumn{5}{|l|}{ Age category, n (\%) } \\
\hline 40-64 years & $3,035(46.5)$ & $2,203(48.4)$ & $832(42.3)$ & \multirow[t]{2}{*}{$<0.00$ I } \\
\hline$\geq 65$ years & $3,486(53.5)$ & $2,352(51.6)$ & $\mathrm{I}, 134(57.7)$ & \\
\hline Female, n (\%) & $3,595(55.1)$ & $2,526(55.5)$ & $1,069(54.4)$ & 0.421 \\
\hline \multicolumn{5}{|l|}{ Region, n (\%) } \\
\hline Northeast & $\mathrm{I}, 159(17.8)$ & $853(18.7)$ & $306(15.6)$ & \multirow[t]{5}{*}{$<0.00$ I } \\
\hline North central & $2,633(40.4)$ & I,839 (40.4) & $794(40.4)$ & \\
\hline South & $2,089(32.0)$ & I,44I (31.6) & $648(33.0)$ & \\
\hline West & $555(8.5)$ & $356(7.8)$ & $199(10.1)$ & \\
\hline Unknown & $85(1.3)$ & $66(1.4)$ & $19(1.0)$ & \\
\hline \multicolumn{5}{|l|}{ Comorbidity in the pre-index period } \\
\hline $\mathrm{CCl}^{\mathrm{b}}$, mean $(\mathrm{SD})$ & $0.65(1.2)$ & $0.66(1.2)$ & $0.64(I . I)$ & 0.600 \\
\hline Number of unique prescription classes, mean (SD) & $9.4(6.2)$ & $9.2(6.0)$ & $9.9(6.5)$ & $<0.00$ I \\
\hline Number of unique diagnoses ${ }^{c}$, mean (SD) & $9.4(7.7)$ & $9.0(7.5)$ & $10.2(8.1)$ & $<0.00 \mathrm{I}$ \\
\hline \multicolumn{5}{|l|}{ Specific comorbidities, $\mathrm{n}(\%)$} \\
\hline Asthma & $896(13.7)$ & $562(12.3)$ & $334(17.0)$ & $<\mathbf{0 . 0 0 1}$ \\
\hline Depression & $840(12.9)$ & $532(11.7)$ & $308(15.7)$ & $<0.00 \mathrm{I}$ \\
\hline URTI & $1,236(19.4)$ & $876(19.2)$ & $387(19.7)$ & 0.671 \\
\hline LRTI & $2,443(37.5)$ & $1,640(36.0)$ & $803(40.8)$ & $<0.00$ I \\
\hline CVD & $3,325(51.0)$ & $2,275(49.9)$ & $\mathrm{I}, 050(53.4)$ & 0.010 \\
\hline \multicolumn{5}{|l|}{ Proxies for COPD severity in pre-index period } \\
\hline Inhaled SAMA use, $\mathrm{n}(\%)$ & $956(14.7)$ & $590(13.0)$ & $366(18.6)$ & $<0.001$ \\
\hline SABA canister use, $\mathrm{n}(\%)$ & $2,160(33.1)$ & $\mathrm{I}, 468(32.2)$ & $692(35.2)$ & 0.019 \\
\hline OCS prescription use, $\mathrm{n}(\%)$ & $2,222(34.1)$ & $\mathrm{I}, 490(32.7)$ & $732(37.2)$ & $<0.00$ I \\
\hline Antibiotic use, $\mathrm{n}(\%)$ & $4,068(62.4)$ & $2,825(62.0)$ & $1,243(63.2)$ & 0.357 \\
\hline Home oxygen therapy use, $\mathrm{n}(\%)$ & $556(8.5)$ & $333(7.3)$ & $223(11.3)$ & $<0.00$ I \\
\hline Mechanical ventilation/intubation during any hospital/ED visit, $\mathrm{n}(\%)$ & $36(0.6)$ & $23(0.5)$ & $13(0.7)$ & 0.434 \\
\hline Any COPD exacerbation, $\mathrm{n}(\%)$ & $809(12.4)$ & $499(11.0)$ & $310(15.8)$ & $<0.001$ \\
\hline COPD-related total costs, mean (SD) & US\$576 (US\$2,912) & US\$457 (US\$2,186) & US\$852 (US\$4,I I 8$)$ & $<0.00$ I \\
\hline \multicolumn{5}{|l|}{ Index exacerbation type ${ }^{d}, \mathrm{n}(\%)$} \\
\hline Hospitalization & $3,370(51.7)$ & $2,594(56.9)$ & $776(39.5)$ & \multirow[t]{2}{*}{$<0.00$ I } \\
\hline ED & $3,15 \mid(48.3)$ & $1,961(43.1)$ & $\mathrm{I}, 190(60.5)$ & \\
\hline \multicolumn{5}{|l|}{ Index exacerbation diagnosis ${ }^{\mathrm{d}}, \mathrm{n}(\%)$} \\
\hline Emphysema (492.xx) & $119(1.8)$ & 85 (1.9) & $34(1.7)$ & \multirow[t]{3}{*}{$<0.00 \mathrm{I}$} \\
\hline Chronic bronchitis (49I.xx) & $5,88 \mathrm{I}(90.2)$ & $4,144(91.0)$ & I,737 (88.4) & \\
\hline Chronic airway obstruction (496.xx) & $521(8.0)$ & $326(7.2)$ & $195(9.9)$ & \\
\hline
\end{tabular}

Notes: a Values in bold are statistically significant (Student's $t$-test for continuous and chi-square for categorical variables). ${ }^{\mathrm{b}} \mathrm{COPD}$, asthma, and cardiovascular disease were excluded from the $\mathrm{CCl}$. ' $\mathrm{A}$ unique count of disease states beyond those used to calculate the $\mathrm{CCl}$ and specific comorbidities is listed. ${ }^{\mathrm{d}}$ These were the only index exacerbation characteristics (excluding maintenance medication prescribed) with a significant difference between the prompt and delayed $M T$ cohorts; index year ( $P=0.23 \mathrm{I}$ ) and season of index date $(P=0.109)$ were not significantly different between the two MT cohorts.

Abbreviations: $\mathrm{CCl}$, Charlson Comorbidity Index; CVD, cardiovascular disease; ED, emergency department; LRTI, lower respiratory tract infection; MT, maintenance treatment; OCS, oral corticosteroids; SABA, short-acting $\beta_{2}$ agonist; SAMA, short-acting anti-muscarinic agent; SD, standard deviation; URTI, upper respiratory tract infection.

These two studies included different MTs (ICS and ipratropium were not included in this study but were included in the study by Dalal et $\mathrm{al}^{14}$ ), which may partially explain the numerical differences reported. The current study therefore confirms the previous findings within a large population with employer-sponsored insurance, as the initiation of MT within 30 days of an exacerbation reduced costs, even with a different assortment of MTs included.

The occurrence of an exacerbation is known to increase the risk of subsequent exacerbations ${ }^{23}$ and may also decrease lung function. ${ }^{24,25}$ The results of this real-world claims data analysis are in agreement with clinical trial data demonstrating that MT may reduce the frequency of subsequent exacerbations. ${ }^{26,27}$ Another study also indicated that the early use of MT benefits patients through improvements in their general health status as assessed by the COPD Assessment Test. ${ }^{28}$ In combination, these results suggest that the timing of MT initiation is an important consideration to optimize patient outcomes. 


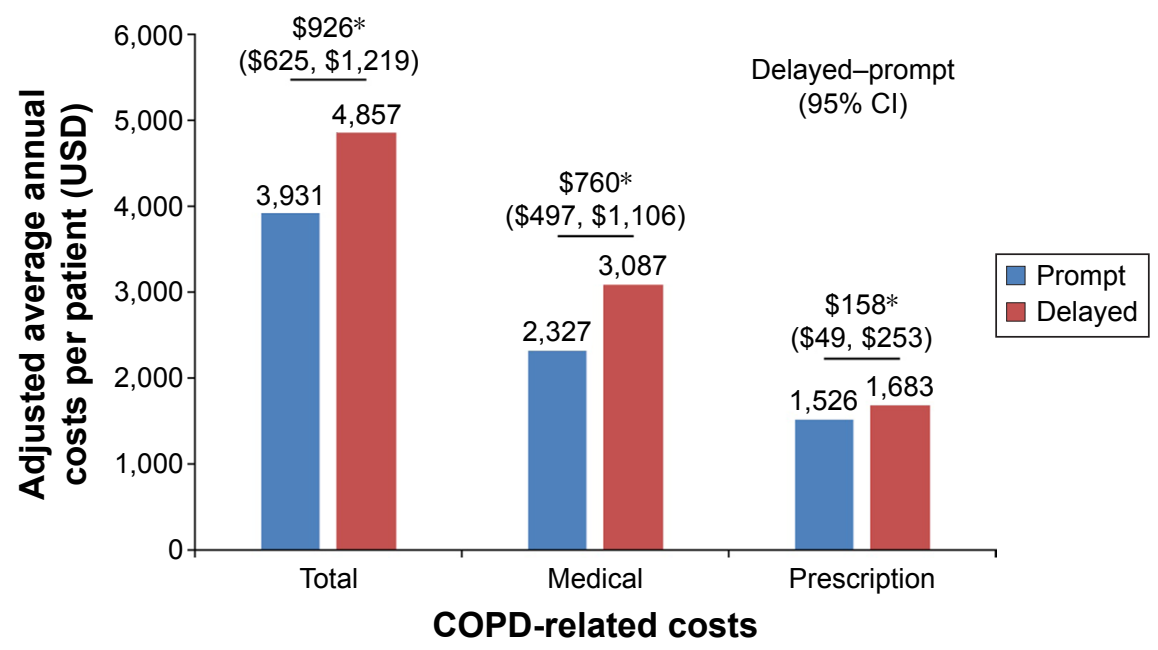

Figure 2 Adjusted annual costs per patient according to MT initiation cohort (prompt $=0-30$ days; delayed $=31-180$ days).

Notes: $* P<0.010$. Adjusted costs obtained from statistical model: semilog OLS controlling for age, sex, region, comorbidity, COPD severity (including pre-index COPDrelated total costs), and type of index exacerbation. A two-part semilog OLS model was used for medical costs.

Abbreviations: $\mathrm{Cl}$, confidence interval; MT, maintenance treatment; OLS, ordinary least squares.
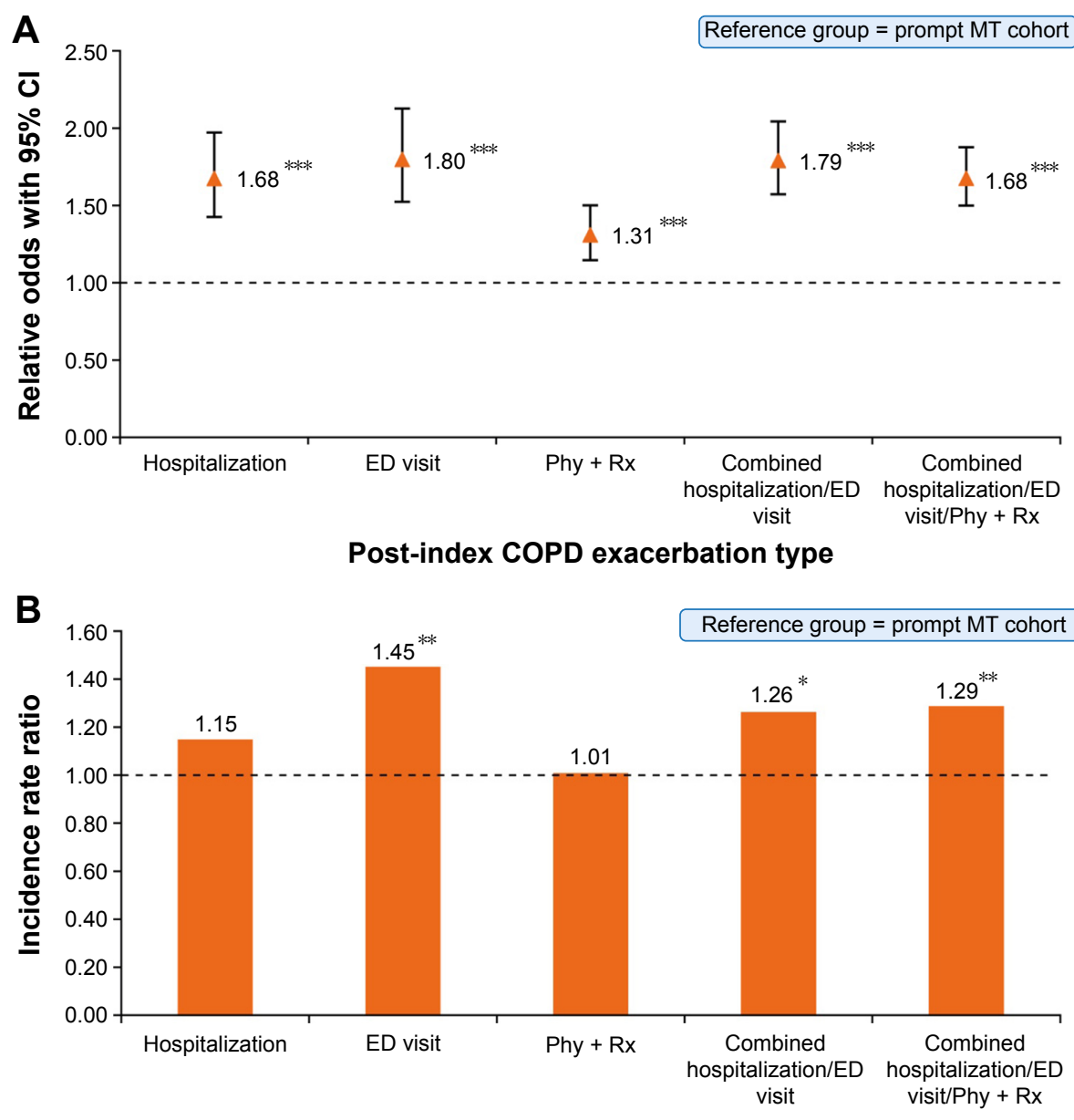

Post-index COPD exacerbation type

Figure 3 (A) Adjusted relative odds of subsequent COPD exacerbation and (B) adjusted relative exacerbation incident rate ratio for the delayed MT cohort (prompt $=0-30$ days; delayed $=31-180$ days).

Notes: $* P<0.050 ; * * P<0.010 ; * * * P<0.001$. Dashed lines at 1.00 indicate the reference lines. Relative odds obtained from logistic regression model estimating likelihood of an event controlling for index exacerbation type and baseline covariates. Incidence rate ratio obtained from zero-inflated negative binomial regression model estimating likelihood of an event controlling for index exacerbation type and baseline covariates.

Abbreviations: $\mathrm{Cl}$, confidence interval; ED, emergency department; MT, maintenance treatment; OCSs, oral corticosteroids; Phy + Rx, physician visit with a prescription for OCSs and/or antibiotics in the subsequent 5 days. 


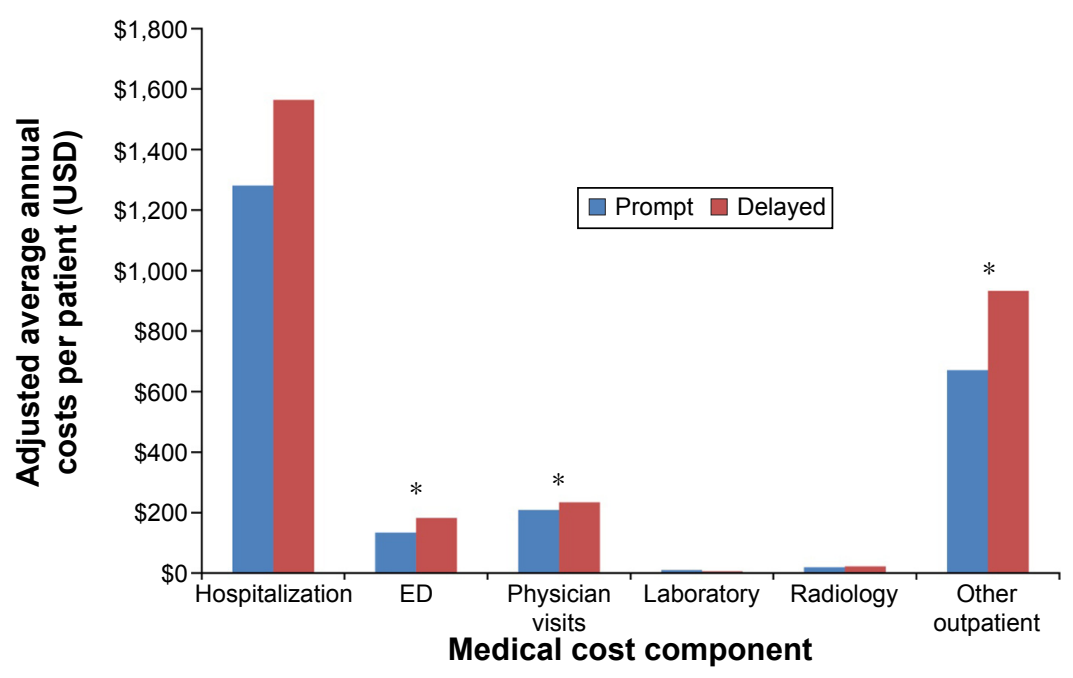

Figure 4 Adjusted annual cost per patient by medical component (prompt $=0-30$ days; delayed $=31-180$ days).

Notes: $* P<0.050$. Adjusted costs obtained from statistical model: a two-part generalized linear model controlling for age, sex, region, comorbidity, COPD severity (including pre-index COPD-related total costs), and type of index exacerbation.

Abbreviation: ED, emergency department.

The most recent GOLD and American College of Chest Physicians/Canadian Thoracic Society (ACCP/CTS) guidelines recommend MT for patients with COPD as it is associated with a reduction in the risk of further exacerbations. ${ }^{1,29}$ Although both the GOLD and ACCP/CTS guidelines have specific recommendations on the use and duration of oral or intravenous systemic steroid treatment after an exacerbation, ${ }^{1,29}$ only the ACCP/CTS guidelines include a specific recommendation on when MT should begin after such an event. ${ }^{29}$ This study, in conjunction with that by Dalal et al, ${ }^{14}$ suggests that MT initiation within 30 days provides significant benefits to patients (fewer subsequent exacerbations) and payers (reduction in costs).

There is evidence to suggest that MT is underutilized in patients with COPD, ${ }^{5,30}$ as $66 \%-71 \%$ of patients in US health plans receive no MT. ${ }^{30}$ Increased awareness of the benefits of MT may help to redress this imbalance and, therefore, improve patient outcomes and the quality of care. The results of this study could provide additional evidence to support the new National Quality Foundation COPD measure, which assesses the number of patients readmitted to hospital in the 30-day post-exacerbation period. ${ }^{9}$ Prompt initiation of MT may help hospitals, payers, and providers to improve their performance as assessed by the measure ${ }^{9}$ recently implemented by Centers for Medicare and Medicaid Services. ${ }^{10}$ The overall impact of prompt MT initiation could ultimately reduce the economic burden of COPD.

Selection bias within the patient cohorts was a potential limitation of this study. Patients within the prompt MT cohort were hypothesized to have more severe COPD vs the delayed MT cohort, as they were treated earlier. However, the delayed
MT cohort was found to have more comorbid conditions and more severe COPD than the prompt MT cohort. Instead, this could be explained by "healthy user bias", where patients who have healthier behaviors are more likely to seek preventative care than their counterparts. ${ }^{31}$ Although the multivariable analyses included adjustments for these baseline covariates to minimize the effect of this limitation, residual confounding may still be present. An inherent limitation of claims data is the lack of clinical information such as $\mathrm{FEV}_{1}$ to more precisely control for severity, which led to our proxy measures. Select common comorbidities indicative of severe disease were adjusted for, however this list of comorbidities was not exhaustive. COPD-related medical costs were those reflected on medical claims with a primary diagnosis of COPD. This may have led to an underestimation of COPD-related costs due to the exclusion of costs related to COPD sequelae, eg, pulmonary hypertension. Survival bias may also have been introduced, as patients had to remain within a health care plan, although switching between plans was permitted, for 1 -year post-index. A final limitation that should be noted is that indicators for the use of acute-care treatment protocols or medications given to the patient while in the hospital, which could be used differently across the cohorts, are not available in claims data.

\section{Conclusion}

Prompt initiation of MT within 30 days following discharge from a COPD-related hospitalization or an ED visit was associated with a significant reduction in adjusted COPD-related costs and odds of subsequent COPD-related exacerbations compared with delayed MT initiation. 


\section{Acknowledgments}

This study was funded by GlaxoSmithKline (GSK; study identifier: 201514). Editorial assistance in the form of developing the first draft based on author input, referencing, editing, and incorporation of author comments was provided by Gillian Groeger, PhD, Fishawack Indicia Ltd, UK.

\section{Author contributions}

Anna D Coutinho contributed to the concept and design of the study, acquisition of the data, and data analysis and interpretation. Tasneem Lokhandwala analyzed and interpreted the data. Robert L Boggs and Anand A Dalal contributed to the study concept and design and also analyzed and interpreted the data. Pamela B Landsman-Blumberg was involved with the study design and data acquisition. Julie Priest analyzed and interpreted the data. David A Stempel contributed to the study concept and design and also analyzed and interpreted the data. All authors contributed to drafting and revising the manuscript and have approved the final version for submission. All authors agree to be accountable for all aspects of the work.

\section{Disclosure}

Anna D Coutinho, Tasneem Lokhandwala, and Pamela B Landsman-Blumberg are employees of Xcenda LLC, a consultancy company contracted by GSK to complete this study. Robert L Boggs and Anand A Dalal were employees of GSK at the time the study was performed and still own GSK stock. Julie Priest and David A Stempel are employees of GSK and owners of stock in GSK. The authors report no other conflicts of interest in this work.

\section{References}

1. GOLD [homepage on the Internet]. Global strategy for the diagnosis, management and prevention of chronic obstructive pulmonary disease; 2015. Available from: $\mathrm{http}: / /$ www.goldcopd.com/. Accessed on March 10, 2015.

2. Blanchette CM, Dalal AA, Mapel D. Changes in COPD demographics and costs over 20 years. J Med Econ. 2012;15(6):1176-1182.

3. Dalal AA, Christensen L, Liu F, Riedel AA. Direct costs of chronic obstructive pulmonary disease among managed care patients. Int JChron Obstruct Pulmon Dis. 2010;5:341-349.

4. Patel JG, Nagar SP, Dalal AA. Indirect costs in chronic obstructive pulmonary disease: a review of the economic burden on employers and individuals in the United States. Int J Chron Obstruct Pulmon Dis. 2014; 9:289-300.

5. Blanchette CM, Gross NJ, Altman P. Rising costs of COPD and the potential for maintenance therapy to slow the trend. Am Health Drug Benefits. 2014;7(2):98-106.

6. ACCP/ATS Pulmonary Measure Gap Task Force [webpage on the Internet]. Measure Gap Areas in Pulmonary Medicine: position paper; 2012. Available from: http://www.chestnet.org/Guidelines-and-Resources/ Health-Policy/Position-Papers. Accessed July 9, 2015.
7. Kahn JM, Gould MK, Krishnan JA, et al; ATS Ad Hoc Committee on the Development of Performance Measures from ATS Guidelines. An official American thoracic society workshop report: developing performance measures from clinical practice guidelines. Ann Am Thorac Soc. 2014;11(4):S186-S195.

8. Cantrell CR, Priest JL, Cook CL, Fincham J, Burch SP. Adherence to treatment guidelines and therapeutic regimens: a US claims-based benchmark of a commercial population. Popul Health Manag. 2011; 14(1):33-41.

9. National Quality Measures Clearinghouse [webpage on the Internet]. Chronic obstructive pulmonary disease (COPD): hospital 30-day, allcause, risk-standardized readmission rate following acute exacerbation of COPD hospitalization; 2014; Available from: http://www.qualitymeasures. ahrq.gov/content.aspx?id=48201. Accessed October 6, 2015.

10. Department of Health and Human Sciences USA. Centers for Medicare and Medicaid Services; Federal Register. Vol. 79, Book 2 of 2 Books, 49853-50536; 2014. Available from: https://www.gpo.gov/fdsys/pkg/ FR-2014-08-22/pdf/2014-18545.pdf. Accessed on October 6, 2015.

11. Calverley PM, Anderson JA, Celli B, et al; TORCH Investigators. Salmeterol and fluticasone propionate and survival in chronic obstructive pulmonary disease. $N$ Engl J Med. 2007;356(8):775-789.

12. Tashkin DP, Celli B, Senn S, et al. A 4-year trial of tiotropium in chronic obstructive pulmonary disease. $N$ Engl J Med. 2008;359(15): 1543-1554.

13. Hanania NA. Optimizing maintenance therapy for chronic obstructive pulmonary disease: strategies for improving patient-centered outcomes. Clin Ther. 2007;29(10):2121-2123.

14. Dalal AA, Shah MB, D'Souza AO, Dhamane AD, Crater GD. Outcomes associated with timing of maintenance treatment for COPD exacerbation. Am J Manag Care. 2012;18(9):e338-e345.

15. GOLD [homepage on the Internet]. Global strategy for the diagnosis, management and prevention of chronic obstructive pulmonary disease; 2014. Available from: http://www.goldcopd.com/. Accessed October 7, 2014.

16. Centers for Disease Control and Prevention [webpage on the Internet]. International Classification of Diseases, Ninth Revision, Clinical Modification; 2011. Available from: http://www.cdc.gov/nchs/icd/icd9cm. htm\#ftp. Accessed August 4, 2015.

17. US Bureau of Labor Statistics [webpage on the Internet]. Consumer Price Index; 2013. Available from: http://www.bls.gov/cpi/. Accessed June, 2013.

18. Burge $\mathrm{S}$, Wedzicha JA. COPD exacerbations: definitions and classifications. Eur Respir J Suppl. 2003;41:46s-53s.

19. Manning WG, Mullahy J. Estimating log models: to transform or not to transform? J Health Econ. 2001;20(4):461-494.

20. Duan N. Smearing estimate: a non-parametric retransformation method. J Am Stat Assoc. 1983;78(383):605-610.

21. Romano PS, Roos LL, Jollis JG. Adapting a clinical comorbidity index for use with ICD-9-CM administrative data: differing perspectives. J Clin Epidemiol. 1993;46(10):1075-1079. [discussion 1081-1090].

22. Charlson ME, Pompei P, Ales KL, MacKenzie CR. A new method of classifying prognostic comorbidity in longitudinal studies: development and validation. J Chronic Dis. 1987;40(5):373-383.

23. Hurst JR, Vestbo J, Anzueto A, et al; Evaluation of COPD Longitudinally to Identify Predictive Surrogate Endpoints (ECLIPSE) Investigators. Susceptibility to exacerbation in chronic obstructive pulmonary disease. N Engl J Med. 2010;363(12):1128-1138.

24. Donaldson GC, Seemungal TA, Bhowmik A, Wedzicha JA. Relationship between exacerbation frequency and lung function decline in chronic obstructive pulmonary disease. Thorax. 2002;57(10):847-852.

25. Makris D, Moschandreas J, Damianaki A, et al. Exacerbations and lung function decline in COPD: new insights in current and ex-smokers. Respir Med. 2007;101(6):1305-1312.

26. Decramer M, Celli B, Kesten S, Lystig T, Mehra S, Tashkin DP. Effect of tiotropium on outcomes in patients with moderate chronic obstructive pulmonary disease (UPLIFT): a prespecified subgroup analysis of a randomised controlled trial. Lancet. 2009;374(9696):1171-1178. 
27. Jenkins CR, Jones PW, Calverley PM, et al. Efficacy of salmeterol/ fluticasone propionate by GOLD stage of chronic obstructive pulmonary disease: analysis from the randomised, placebo-controlled TORCH study. Respir Res. 2009;10:59.

28. Jahnz-Rozyk K, Szepiel P. Early impact of treatment with tiotropium, long-acting anticholinergic preparation, in patients with COPD - reallife experience from an observational study. Int J Chron Obstruct Pulmon Dis. 2015;10:613-623.

29. Criner GJ, Bourbeau J, Diekemper RL, et al. Prevention of acute exacerbations of COPD: American College of Chest Physicians and Canadian Thoracic Society Guideline. Chest. 2015;147(4):894-942.
30. Make B, Dutro MP, Paulose-Ram R, Marton JP, Mapel DW. Undertreatment of COPD: a retrospective analysis of US managed care and Medicare patients. Int J Chron Obstruct Pulmon Dis. 2012;7:1-9.

31. Shrank WH, Patrick AR, Brookhart MA. Healthy user and related biases in observational studies of preventive interventions: a primer for physicians. J Gen Intern Med. 2011;26(5):546-550.

International Journal of COPD

\section{Publish your work in this journal}

The International Journal of COPD is an international, peer-reviewed journal of therapeutics and pharmacology focusing on concise rapid reporting of clinical studies and reviews in COPD. Special focus is given to the pathophysiological processes underlying the disease, intervention programs, patient focused education, and self management protocols.

\section{Dovepress}

This journal is indexed on PubMed Central, MedLine and CAS. The manuscript management system is completely online and includes a very quick and fair peer-review system, which is all easy to use. Visit http://www.dovepress.com/testimonials.php to read real quotes from published authors.

Submit your manuscript here: http://www.dovepress.com/international-journal-of-chronic-obstructive-pulmonary-disease-journal 